\title{
CIVIC PARTICIPATION AND THE DEVELOPMENT OF ADOLESCENT BEHAVIOR PROBLEMS
}

Alessio Vieno

University of Padova

Maury Nation and Douglas D. Perkins

Vanderbilt University

Massimo Santinello

University of Padova

This study assessed the links between civic participation and adolescent behavior problems (bullying, physical fighting, and alcohol and tobacco use), and whether civic engagement could be a moderator of the negative effects of parent/family detachment. Participants were 7,097 11-, 13-, and 15 -year-olds (48.6\% girls) in a region of Northern Italy. Twenty percent were involved in some level of civic participation, the majority of which was faith-based. Results showed that adolescents who are involved in civic associations reported slightly less fighting and alcohol and tobacco use, but this relationship varies by sex, age, detachment from parents and family, and the frequency of adolescent participation. For the sample as a whole, a U-shaped relationship was found between civic participation and behavior problems, with the fewest behavior problems associated with moderate frequency of participation (1 to 4 times per week). The expected hypothesis that civic participation moderates the relationship between parent/family detachment and problem behaviors was suggested only for 15-year-old girls but not for younger girls or for boys. Implications for preventive interventions are discussed. (c) 2007 Wiley Periodicals, Inc.

The efforts to reduce or change antisocial or deviant behavior during adolescence have shown limited effectiveness (Mrazek \& Haggerty, 1994; Trembley \& Craig, 1995). Some of these programs focus on conflict resolution and anger management, life skills training, or self-esteem development, and still others employ the use of police

The HBSC study in Veneto is funded by Regione Veneto (D.G.R. n 203 of April 4, 2000).

Correspondence to: Alessio Vieno, Department of Developmental and Social Psychology, Via Belzoni, 80, 35131 Padova, Italy. E-mail:alessio.vieno@unipd.it 
patrols and metal detectors (O'Donnell et al., 1999). However, it is possible to reduce adolescent behavior problems in two ways: one is to prevent the onset of problem behaviors through universal or targeted interventions designed to address adolescents' risks and deficits; a second approach is youth development-focused interventions designed to enhance the range of adolescents' competencies and interests (Cowen, 1994). Based on more recent theories that the development of social competence and social skills is critical to the reduction of risky behaviors, participation in a community organization may provide youth with opportunities to practice decision making, communication, goal-setting, self-assessment, and self-management skills. This article considers adolescents' civic participation as serving the two protective functions identified by Cowen: 1: as a form of positive social engagement to help inoculate "normal" youths from developing behavior problems and, 2: to moderate the effects of poor family-adolescent relationships for adolescent at risk for poor social and behavior outcomes.

Research on adolescent engagement has mainly investigated participation in extracurricular structured activities such as sports, youth groups, hobby, or special interest groups. Civic participation in community service organizations, including religious congregations, school-based service clubs, scouts, neighborhood voluntary associations, and political action or advocacy groups, can help youths to think of (a) others who have greater needs than they do, (b) themselves as able to make a difference in people's lives, and (c) their community as a place they belong and with which they can identify (Nation, Wandersman \& Perkins, 2002; Perkins, Crim, Silberman, \& Brown, 2003; Pretty, 2002). Therefore, the question is not whether the adolescent participates, but in what is the adolescent participating? For these reasons, we focus on the impact of such forms of youth civic engagement on participants' involvement in risky or antisocial behaviors.

\section{Civic Participation}

According to ecological theory, adolescents' every day activities are important developmental phenomena, and the content of activities can be seen as an important index of psychosocial adjustment (Bronfenbrenner, 1979) and as a forum for the socialization of cultural knowledge and practices (McHale, Crouter, \& Tucker, 2001). In fact, from a developmental perspective, analysis of time use can show whether adolescents are taking advantage of opportunities for learning and practicing competencies and skills (Larson \& Verma, 1999) and receiving social supports that can buffer the effects of disadvantaged or stressful life circumstances or a lack of support from family (Mahoney, Schweder, \& Stattin, 2002). In that sense, Werner (1993) noted the significance of hobbies and extracurricular activities for providing children with "solace in adversity and a reason to feel proud" (p. 509).

Studies have linked adolescents' choice of after-school activity to peer relationships and acceptance (Kinney, 1993; Mahoney, 2000; Sandstrom \& Coie, 1999), school achievement (Bartko \& Eccles, 2003; Eccles \& Barber, 1999), less school dropout (McNeal, 1995), less depressed mood (Mahoney et al., 2002), greater life satisfaction (Gilman, 2001), improved psychological health (Barber, Eccles, \& Stone, 2001; Larson \& Kleiber, 1993), less teenage parenthood (Allen, Philliber, Herrling, \& Kuperminc, 1997), less antisocial behavior (Mahoney \& Stattin, 2000; Yin, Katims, \& Zapata, 1999), less substance use (Youniss, Yates, \& Su, 1997), and less criminal offending (Mahoney, 2000). 
However, there are several limitations in the research on after-school activities particularly as it relates to the concept of civic participation. Most of these studies distinguish between structured extracurricular activities, particularly ones that are physically or mentally stimulating, and unstructured activities in which participants assume a primarily passive role. However, researchers are often less careful in assessing the kinds of associations in which students are involved. Sports activity, in particular, has received a great deal of attention from researchers, although results have been mixed (Barber et al., 2001; Eccles \& Barber, 1999). For example, participation in sports is linked to increased alcohol use (Eitle, Turner, \& Eitle, 2003) and to increased academic achievement and self-esteem (Marsh \& Kleitman, 2003).

Youniss et al. (2002) has noted that there are limited data on young people's involvement in the full spectrum of civic and political activities, and that the general picture that emerges is one of apathy toward traditional politics. Yet, there exists a large number and variety of community organizations catering to youth and thus a tremendous opportunity to mobilize the civic involvement and social and moral development of youth. In countries that provide a full-scale, state-supported, professional human service system, the variety of civic organizations may be more constrained, but a large number of youth and adolescents still engage in different forms of volunteer service with various populations, particularly through religious organizations (Marta, Rossi \& Boccacin, 1999). Adolescents' involvement in volunteer service or participation and engagement in faith-based activities puts youth in contact with people in need, with people from diverse backgrounds, and with positive role models, such as youth leaders or clergy, which can be especially important for at-risk youth (Youniss \& Yates, 1997). Also, it may provide them with an ideological framework for understanding their actions and give them the experience of the self as an agent working within an explicit ideological tradition (Youniss \& Yates). For these reasons in this study, adolescents' participation in extracurricular activity is not focused on unstructured activities that are mostly self-directed and/or motivated mostly from self-interest. Instead, this study is focused specifically on adolescents' participation in civic engagement through organizations in which the activities are likely result in the common good.

Most research on civic engagement has used a dichotomous coding of extracurricular participation (Mahoney, Cairns, \& Farmer, 2003). For many interventions designed to reduce poor outcomes, the amount of intervention the adolescent receives has been a critical aspect of program effectiveness (Nation et al., 2003). Similarly, measuring the frequency of civic participation is needed to determine the amount of involvement necessary to result in other positive behavioral changes for adolescents. Furthermore, measuring the frequency of civic involvement provides an opportunity to examine whether the relationship is linear or whether adolescents can become over-involved.

Finally, most of the studies that have examined civic participation have not considered the mechanisms by which adolescents may benefit from involvement. Some studies have suggested that participation reinforces positive social values and future civic activity (Fletcher, Elder, \& Mekos, 2000), while others have suggested that it reduces the unstructured free time that youths might otherwise use in counterproductive ways (Larson, 2001). This study focuses on the possibility that civic engagement may interact with family relationships to enhance the protection associated with positive family relationship or compensate for the risk associated with difficult or detached family relationships. 


\section{Adolescent Detachment From Parents Or Family And Problem Behavior}

Parental and family relationships have been consistently identified as one of the most important factors in predicting both civic participation (Putnam, 2000) and behavioral problems in children and adolescents. As suggested in ecological theory, family plays a strategic role in child development directly by influencing the set of behaviors children learn as a part of their socialization, and indirectly by influencing the other systems (e.g., peers, school, neighborhood) that influence adolescent behavior (Bronfenbrenner, 1979). Consequently, disruptions in family relationships can have profound effects on a child's psychosocial development and predispose children to develop a variety of behavioral problems (Dishion \& Bullock, 2002; Dodge, 2001). In the case of alcohol and drug use, for example, the research suggests that detachment in the form of either physical or emotional absence or relationships high in conflict or low cohesion can result in higher levels of drug use. Labouvie, Pandina, and Johnson's (1991) study of 400 adolescents found several variables including maternal warmth and parental alcoholism were significant predictors of adolescent alcohol use. In a related longitudinal study (Johnson \& Pandina, 1991), they found that a hostile relationship, a lack of warmth, and father's alcohol use were among the most important predictors of higher levels of drug use among adolescents. A study of the impact of physically absent fathers found that having a nonresident father placed both Black and White and adolescents at increased risk of heavy drinking and drug use (Thomas, Farrell, \& Barnes, 1996).

Studies of bullying have also indicated that the quality of the parent-child relationship is an important factor in development of behavior problems. Olweus (1993), for example, described the families of bullies as not very engaged and, in some cases, actively hostile toward the child. Also, he suggested that other problems including parental conflict, divorce, and alcohol and drug problems might contribute to the development of bullying behavior. This is consistent with Curtner-Smith's (2000) study of mother-child dyads, which found that family processes, particularly modeling variables (e.g., marital satisfaction and social support) were important predictors of bullying behaviors. Directly addressing the issue of parental involvement, Flouri and Buchanan (2003) found that low involvement of both fathers and mothers uniquely contributed to the frequency of bullying behavior.

The literature on more overt forms of adolescent aggression and violence provide additional evidence of the link between parent-child relationships and behavior problems. In a study of violence and delinquency, Henry, Tolan, and Gorman-Smith (2001) constructed a variable of family well-being from several family characteristics, including family cohesion and parenting skills, and found this variable was an important predictor of poor outcomes. A similar study comparing violent and nonviolent offenders found that the violent offenders reported less cohesion and poorer discipline than the comparison groups (Gorman-Smith, Tolan, Zelli, \& Huesmann, 1996). Other studies have confirmed that aggressive and violent children have low involvement with their families and often receive little supervision (Farrington, Loeber, Yin, \& Anderson, 2002).

This brief review of the role of family in adolescent substance abuse and behavioral problems suggests both direct and indirect mechanisms connecting the variables. Modeling problem behaviors and providing insufficient supervision are direct influences on substance abuse (Barnes, Reifman, Farrell, \& Dintcheff, 2000), bullying, and 
aggression (Espelage, Bosworth, \& Simon, 2000). This research also suggests that the quality of the family relationship might play an important role in determining the type of peer relationships a child develops (Chassin, Curran, Hussong, \& Colder, 1996; Garnier \& Stein, 2002). In either case, civic participation may be one method of moderating the effects of poor parent-child relationships by providing a structure for increased supervision and providing a forum for developing adaptive relationships with adults and peers.

\section{Objectives of the Study}

To understand adolescent civic participation and how it fits into ecological framework for developing effective community-wide programs to prevent antisocial and promoting healthy youth development, it is important to examine representative data on adolescents' involvement in civic associations and its relationship to various problem behaviors. It is also important for purposes of external validation across cultural, political, and other contexts to consider data from outside North America, where much of the research on civic participation, prevention, health, and social behavior of adolescents has occurred. Toward these goals, the present study explores the frequency of participation in predominantly faith-based civic associations of a representative sample of 11, 13, and 15-year-old boys and girls in a Northern Italian region and the relationship of such participation to problem behaviors, such as bullying, physical fighting, and alcohol and tobacco use. In addition, this study assesses whether involvement in civic organizations can enhance the developmental context in a way that protects or buffers children from some of the deleterious effects (i.e., problem behaviors) associated with detached relationships with their parents and family.

Based on the above-mentioned overview of the literature, there are three hypotheses for the study. First, in accordance with previous research we expect that adolescents who report detached relationship with parents and family will show high rates of problem behavior. Second, we hypothesize that adolescents who participate in civic associations will show lower rates of problem behavior. Finally, we expect an interaction effect between civic participation and parent/family detachment, which would suggest that participation buffers the effect of detachment on problem behaviors. The assumption of this last hypothesis is that civic participation will be particularly beneficial for the subgroup of adolescents characterized by a detached relationship with parents and family. The analysis of all these hypotheses will include an examination of age and gender because previous research has suggested that these factors may influence the quality of parental and family relationships (e.g., Biederman, Faraone, \& Monuteaux, 2002; Formoso, Gonzales, \& Aiken, 2000), and have an impact on the frequency of problem behaviors (e.g., Olweus, 1993; Sale, Sambrano, Springer, \& Turner, 2003). Parent education level will be included as a control variable as it may also predict adolescent problem behavior (Brown, Schulenberg, Bachman, O'Malley, \& Johnston, 2001; Lintonen, Rimpelae, Vikat, \& Rimpelae, 2000).

\section{METHOD}

\section{Procedures}

This study was carried out in the Veneto region of northeastern Italy. The region has a population of 4,540,853 citizens, with 351 middle schools serving 120,419 students 
and 231 high schools serving 165,866 students. The Veneto is the wealthiest region in the country: The incidence of families living below the poverty level in this region is $5.7 \%$, as compared to a national average of $12.3 \%$. The ethnic composition is very homogeneous: The percentage of immigrant students is less than $3 \%$.

The data presented in this study are from a Regional (Veneto, Italy) research project that is part of the "Health Behavior in School-aged Children" (HBSC) project, a trans-national study carried out in collaboration with the European office of the World Health Organization (Aarø, Wold, Kannas, \& Rimpelä, M., 1986). The research protocol included three age groups: 11,13 and 15 corresponding to the 6 th, 8 th, and 10 th grades (1st and 3rd grade of Italian middle school, and 2nd grade of Italian secondary school).

The participants responded to the questionnaires as a part of the regular school day and were assured of the confidentiality of their answers. After 2 hours of survey training, classroom teachers administered the questionnaire at the school.

\section{Participants}

Participants were chosen through a "sample clustering" approach: First, the schools were randomly selected from the Regional School Office's data base (96 from 351 middle school, and 109 from 231 high school), and then in each school one class for each age group was selected randomly. Two-stage cluster sampling was used to select the sample (Thompson, 1999): schools were first selected, and then classes were selected from this sample. The sample includes all students in the selected classes. This particular design ensures a sample population that accurately reflects the referent population.

The questionnaire was completed by a total of 7,097 students. The average age of each of the three age groups 11.69 years $(N=2,249)$; 13.74 years $(N=2,246)$; and 15.85 years $(N=2,602)$. The sample is made up of 3,650 boys $(51.4 \%)$ and 3,447 girls $(48.6 \%)$.

\section{Measures}

Data were collected through a self-report questionnaire, devised in 2001-2002 by the HBSC international group, in which early adolescents' and adolescents' main health behaviors are investigated. Only data related to civic participation, family detachment, problem behavior, and SES are included and will be analyzed for the present study.

Participation. Adolescents were surveyed about their frequency of participation in any kind of club or organization (e.g., youth club, swimming/athletics club, choir, dance, church, etc.). Response options are as follows: $1=$ not at all; $2=$ less than once a week; $3=$ once or twice; $4=$ three or four days a week; $5=$ five or six days a week; $6=$ every day of the week. Participants were also asked an open-ended question to indicate the type of association in which they were participating. These responses were coded into eight categories: Sports, Formative (religious, scouting, etc.), Expressive (dance, theatre, and fine arts), Cultural (research, library), Ecological (Environmental League, World Wildlife Federation, etc.), Voluntary, Political, Other. Only participation in associations with a civic mission (Formative, Cultural, Ecological, Voluntary, and Political) were included in the present analyses. Participation in Formative organizations accounted 
for $97.7 \%$ of those who were civically engaged and the vast majority of those participated in church-based community service.

Detachment from parents and family. The level of detachment in parent-adolescent and adolescent-family relationships was generated by a composite score composed from parental monitoring, support and family life subscales. Five items (for both parents) assessed parental monitoring of adolescent leisure time after school (Rispens, Hermanns, \& Meeus, 1997). Responses were rated on a 3-point scale ( $1=$ she/he knows a lot; $2=$ she/he knows a little; $3=$ she/he doesn't know anything). The scale items are as follows: How much does your mother/father really know about ... (1) Who your friends are; (2) How you spend your money; (3) Where you are after school; (4) Where you go at night; (5) What you do with your free time. Alpha reliability for the 5-item scale was .77 for mother and .87 for father. The mother and father indicators were correlated $r=.60(p<.001)$.

Four items (for both parents) assessed parental support of adolescent (part of the scale proposed by Parker, Tupling, \& Brown, 1979). Responses were rated on a 3-point scale $(1=$ almost always; $2=$ sometimes; $3=$ never $)$. The scale items are as follows: My mother/father ... (1) Helps me as much as I need; (2) Is loving; (3) Understand my problems and worries; (4) Make me feel better when I am upset. Alpha reliability for the 5-item scale was .77 for mother and .66 for father. The correlation between the two parental indicators was $r=.50(p<.01)$.

Eight items assessed family life of adolescents (Sweeting, West, \& Richards, 1998). Responses were rated on a 5-point scale $(1=$ every day; $2=$ most days; $3=$ about once $a$ week; 4 = less often; 5 = never). The scale items are as follows: How often do you and your family usually do each of these things together? (1) Watch TV or a video together, (2) Play indoor games together, (3) Eat a meal together, (4) Go for a walk together, (5) Go places together; (6) Visit friends or relatives together; (7) Play sport together, (8) Sit and talk about things together. Alpha reliability for the 8-item scale was .80.

The three subscales were averaged to form a composite measure of the level of parent-adolescent detachment. Parent-adolescent relationship detachment was classified trichotomously according to the following criteria (Mahoney et al., 2002): low detachment for adolescents in the top $20 \%$ of the (attachment) distribution; moderate detachment for those in the middle $60 \%$ range of the distribution; high detachment for those in the bottom $20 \%$ of the distribution.

Problem behavior. Three different kinds of adolescent problem behaviors are analyzed. One item measured "During the past 12 months, how many times were you in a physical fight?" (Brener, Collins, Kann, Warren, \& Williams, 1995). Responses were rated on a 5 -point scale $(1=$ never; $2=$ one time; $3=$ two times; $4=$ three times; $5=$ four times or more). Second item assesses the bullying behavior: "How often have you taken part in bullying another student at school in the past couple of months?" (Olweus, 1996). Response were rated on a 5 -point scale $(1=$ never, $2=$ one or twice; $3=$ two or three time a month; $4=$ about once a week; $5=$ several times a week).

Two items assessed adolescents' substance use, or "risky," behavior. One was "How often do you smoke tobacco at present?" Responses were rated on a 4-point scale $(1=$ I do not smoke; 2 = less than one a week; $3=$ at least once a week, but not every day; $4=$ every day). The second item assessed drinking behavior: "Have you ever had so much alcohol that you were really drunk?" Responses were rated on a 5-point scale $(1=$ no, never, $2=$ yes, one; $3=$ yes, two-3 times; $4=$ yes, $4-10$ times; $5=$ more than 10). Because of the 
relationship among the two variables $(r=.55, p<.01)$ a composite measure was obtained.

Parents' education. Two items were used to assess the education level of both parents. According to the Italian education system, the responses were rated on a 5-point scale $(1$ = elementary; $2=$ middle school; $3=$ vocational school; $4=$ high school; $5=$ university $)$.

\section{RESULTS}

\section{Preliminary Analyses}

Frequency of civic participation. Between $16 \%$ and $17 \%$ of adolescents in this sample report at least weekly involvement with a civic organization of some type, while $3 \%$ are involved less than once per week and $80 \%$ report no involvement at all. A closer look at the frequency of participation showed that $11 \%$ of all adolescents engaged in organized civic activities once or twice per week, $3.5 \%$ did so 3 or 4 days per week, and about $2 \%$ did so 5 or more days per week. Differences in the frequency of youth civic participation among 11-, 13-, and 15-year-olds were significant $\left(F_{(2,7090)}=9.80, p<.01\right)$ and increase from the youngest cohort to the oldest. Post hoc analyses (Least Significant Difference) show statistical differences between the ages of 11 and $13(.13, p<$ $.05)$ and between 11 and $15(.08, p<.05)$ but not between 13 and $15(.05, p>.05)$. Overall, girls are more involved than boys in civic associations $\left(F_{(1,7091)}=45.72, p<\right.$ .01 ). Based on plots of the relationship between participation and each of the three outcomes, a curvilinear pattern emerged that suggested three critical levels of civic involvement; hence, a trichotomous measure was created in which low $=$ none or less then 1 day per week; moderate $=$ between 1 and 4 days; high $=$ more than 5 days per week.

Parent/family-adolescent detachment. Differences between the three age groups in degree of parent-adolescent and family-adolescent detachment are significant $\left(\chi^{2}(2,6526)=\right.$ $524.23, p<.01)$ as detachment increases with age of the child. Girls, more than boys, tend to be more attached to their parents and family $\left(\chi^{2}{ }_{(1,6526)}=20.69, p<.01\right)$. Civic participation and parent/family-adolescent detachment were not significantly related.

\section{Civic Participation, Parent/Family Detachment, And Problem Behavior}

Except for a moderate correlation $(r=.33, p<.01)$ between parent/family detachment and risky (smoking and drinking) behavior, the linear relationships among civic participation, parent/family detachment, and problem behavior are modest to nonsignificant. Risky behavior correlated with civic participation a mere $r=-.035(p<$ $.01)$. Bullying was not significantly correlated to either participation or detachment. Fighting was correlated just at $r=-.06(p<.01)$ to participation and at $r=.09(p<$ .01) to detachment.

A test of the effect of the level of participation on self-reported behavior problems found significant participation level differences exist for each problem behavior. Plots of the conditional means indicated a consistent pattern for each behavior is a U-shped curvilinear relationship with more problems occurring at none and high levels of participation than at the moderate level. The post hoc comparison for all three measures 
Table 1. Means and Standard Deviations Across the Groups

\begin{tabular}{|c|c|c|c|c|}
\hline \multirow[b]{2}{*}{ Item } & \multicolumn{4}{|c|}{ Parent/family detachment } \\
\hline & Low & Moderate & High & Total \\
\hline \multicolumn{5}{|l|}{ Behavior problem } \\
\hline Bullying & $1.40(.80)_{\mathrm{b}, \mathrm{c}}$ & $1.56(.98)_{\mathrm{a}, \mathrm{c}}$ & $1.81(1.18)_{\mathrm{a}, \mathrm{b}}$ & $1.58(1.01)^{* *}$ \\
\hline Physical fight & $1.70(1.22)_{\mathrm{b}, \mathrm{c}}$ & $1.69(1.19)_{\mathrm{a}, \mathrm{c}}$ & $1.93(1.33)_{\mathrm{a}, \mathrm{b}}$ & $1.76(1.24) * *$ \\
\hline \multirow[t]{2}{*}{ Risk behavior } & $2.33(1.01)_{\mathrm{b}, \mathrm{c}}$ & $2.66(1.41)_{\mathrm{a}, \mathrm{c}}$ & $3.66(2.10)_{\mathrm{a}, \mathrm{b}}$ & $2.84(1.62) * *$ \\
\hline & \multicolumn{4}{|c|}{ Civic participation } \\
\hline Item & None & Moderate & High & Total \\
\hline \multicolumn{5}{|l|}{ Behavior problem } \\
\hline Bullying & $1.61(1.04)_{\mathrm{b}}$ & $1.48(.91)_{\mathrm{a}}$ & $1.62(.99)$ & $1.59(1.02) * *$ \\
\hline Physical fight & $1.81(1.27)_{\mathrm{b}}$ & $1.58(1.10)_{\mathrm{a}}$ & $1.87(1.37)$ & $1.77(1.25) * *$ \\
\hline Risk behavior & $2.87(1.67)_{\mathrm{b}}$ & $2.65(1.37)_{\mathrm{a}}$ & $2.75(1.44)$ & $2.84(1.63)^{* *}$ \\
\hline
\end{tabular}

Note. a,b,c indicate differences between groups

$*<.05 ; * *<.01$,

of problem behavior indicates that differences are found between those who indicated no civic involvement and those that indicated moderate civic involvement. Although not significant, we observed the tendency for all three behavior problems to increase in the group with high levels of involvement.

Table 1 also compares problem behaviors for the three levels of detachment from parents and family. Results suggest an upward-sloping curve in which the high detachment group engaged in significantly more of each type of problem behaviors (bullying, fighting, and smoking and drinking) than did the low and moderately detached groups. Except for physical fighting, post hoc comparisons indicate a significant difference also between low and moderate parent and family detachment.

A series of multivariate analyses of variance (MANOVAs) were conducted using civic participation, parent/family detachment, and their interaction as the independent variables along with age, gender, and parents' education as covariates; and bullying behavior, physical fighting, and alcohol and tobacco use served as the dependent variables. Results of the analysis are shown in Tables 2 and 3.

Table 2. Multiple Analyses of Covariance After Controlling for Age, Gender, and SES

\begin{tabular}{|c|c|c|c|c|c|c|}
\hline & $\begin{array}{l}\text { Wilks's } \\
\text { Lambda }\end{array}$ & $F$ & $\begin{array}{c}H y p . \\
d f\end{array}$ & $\begin{array}{c}\text { Error } \\
\text { Df }\end{array}$ & $p$ & $\begin{array}{c}\text { Eta } \\
\text { Square }\end{array}$ \\
\hline \multicolumn{7}{|l|}{ Behavior problem } \\
\hline Intercept & .88 & 283.89 & 3 & 6243 & .00 & .11 \\
\hline Age & .84 & 388.69 & 3 & 6243 & .00 & .16 \\
\hline Gender & .91 & 212.08 & 3 & 6243 & .00 & .09 \\
\hline Fam. education & .99 & 3.44 & 3 & 6243 & .02 & .01 \\
\hline Par./fam. detachment & .98 & 13.03 & 6 & 12486 & .00 & .02 \\
\hline Civic. participation & .99 & 4.26 & 6 & 12486 & .00 & .01 \\
\hline Civic. part. * par./fam. Detach. & .99 & 1.7 & 12 & 16517 & .06 & .00 \\
\hline
\end{tabular}


Table 3. Between Subjects Effects

\begin{tabular}{|c|c|c|c|c|c|c|}
\hline Source & Dependent variable & $S S$ & $d f$ & $M S$ & $F$ & $p$ \\
\hline \multirow[t]{3}{*}{ Corrected model } & Bullying & 267.82 & 11 & 24.35 & 26.05 & .00 \\
\hline & Physical fight & 638.02 & 11 & 58.00 & 66.96 & .00 \\
\hline & Risk behavior & 1518.43 & 11 & 138.04 & 183.30 & .00 \\
\hline \multirow[t]{3}{*}{ Age } & Bullying & 1.10 & 1 & 1.10 & 1.17 & .28 \\
\hline & Physical fight & 49.34 & 1 & 49.34 & 56.96 & .00 \\
\hline & Risk behavior & 730.50 & 1 & 730.50 & 970.00 & .00 \\
\hline \multirow[t]{3}{*}{ Gender } & Bullying & 110.95 & 1 & 110.95 & 118.72 & .00 \\
\hline & Physical fight & 527.20 & 1 & 527.20 & 608.62 & .00 \\
\hline & Risk behavior & 34.20 & 1 & 34.20 & 45.42 & .00 \\
\hline \multirow[t]{3}{*}{ Fam. education } & Bullying & 8.51 & 1 & 8.51 & 9.11 & .00 \\
\hline & Physical fight & .10 & 1 & .10 & .12 & .73 \\
\hline & Risk behavior & .00 & 1 & .00 & .10 & .75 \\
\hline \multirow[t]{3}{*}{ Par./fam. detachment } & Bullying & 17.87 & 2 & 8.93 & 9.56 & .00 \\
\hline & Physical fight & 24.89 & 2 & 12.44 & 14.37 & .00 \\
\hline & Risk behavior & 36.97 & 2 & 18.48 & 24.54 & .00 \\
\hline \multirow[t]{3}{*}{ Civic participation } & Bullying & 6.64 & 2 & 3.32 & 3.55 & .03 \\
\hline & Physical fight & 7.59 & 2 & 3.79 & 4.38 & .01 \\
\hline & Risk behavior & 11.61 & 2 & 5.80 & 7.71 & .00 \\
\hline \multirow[t]{3}{*}{ Civic. part * par./fam. detach. } & Bullying & 2.94 & 4 & .57 & .61 & .65 \\
\hline & Physical fight & 7.11 & 4 & 1.79 & 2.05 & .08 \\
\hline & Risk behavior & 5.93 & 4 & 1.48 & 1.97 & .10 \\
\hline
\end{tabular}

The overall MANOVA (Table 2) revealed significant main effects for age, gender, parents' education, family detachment, and civic participation, and a nearly significant trend for the interaction between civic participation and adolescent-parent/ family detachment. The between subjects effects (Table 3) show significant independent effects of age on physical fighting and alcohol and tobacco use but not on bullying. Fighting decreases while substance use increases with age. Boys predictably engage in significantly more of each problem behavior than girls. Youths whose parents have less education engage in slightly more bullying behavior. Civic participation and family detachment are related to all the indicators of problem behavior. The interaction between civic participation and family detachment was not significantly and independently related to any of the problem behaviors examined.

\section{Civic Participation and Problem Behaviors by Age, Gender, and Level of Family Detachment}

The significant independent effects for parent/family detachment and civic participation require more scrutiny. Univariate analyses and examination of group means revealed that greater family detachment is clearly related to more problem behavior. The situation regarding civic participation and problem behavior appears more complicated: The unexpected U-shape relationship suggests that youth who participate less than once a week or more than four times per week engage in the most bullying, fighting, and alcohol and tobacco use. Other factors that may complicate the relationship between civic participation and problem behaviors include differences between 
the three age groups, gender differences, and degree of attachment to parents and family.

To explore these complicating factors, contrasts were performed to determine if civic participation has a different buffering effect on the relationship between family detachment and each problem behavior for males and females at different ages. To compare the different indicators of problem behavior, standardized scores are used. The contrasts do not become very clear and consistent until age 15, and, for that reason, contrasts are not reported.

To examine the potential buffering effect of participation on problem behaviors among 15-year-olds, Figure 1 presents histograms for boys and girls with high parent/ family detachment and low-, moderate-, and high-levels of participation. For boys, the unexpected U-shaped pattern is clear for each type of problem behavior, with the greatest bullying, fighting, and alcohol and tobacco use by those most frequently involved in civic participation and the least by those moderately involved. This trend is the same for the three cohorts, but is not statistically significant. For 15-year-old girls, the predicted, linear buffering effect of greater civic participation was foundgirls who participated more than four days per week engaged in less bullying $\left(F_{(2,448)}=\right.$ $2.15, p<.05)$ and less alcohol and tobacco use $\left(F_{(2,442)}=3.48, p<.05\right)$. They also got into fewer fights, but that effect was nonsignificant $\left(F_{(2,471)}=0.55, p>.05\right)$.

\section{DISCUSSION}

\section{Summary of Results}

The results provide mixed support for the first two hypotheses-that parent/family detachment is related to adolescent problem behavior and that civic participation is

\section{High Parent and Family Detachment Subgroup}
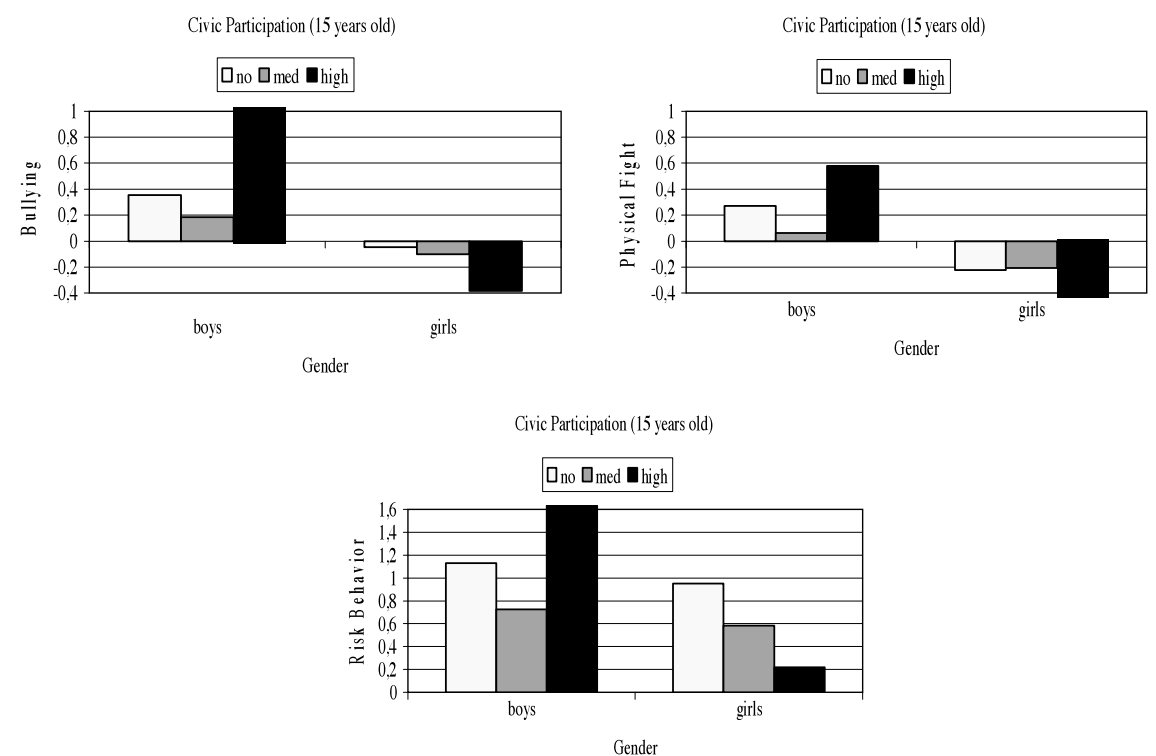

Figure 1. Behavior problem as a function of civic participation and gender for 15-year-olds with high parent and family detachment. 
inversely related to problem behavior-and are generally consistent with previous research. Parent/family detachment was related to problem behaviors, especially tobacco and alcohol use. Otherwise, the linear relationships of both detachment and civic participation with problem behaviors across the whole sample of Italian 11-, 13-, and 15-year-olds were modest in size.

Many other patterns were as expected: Frequency of civic engagement increased from the youngest cohort to the oldest. Fighting decreases and alcohol and tobacco use increase with age. Adolescent detachment from parents and family is greater for the older cohort and for boys.

Our results confirm the importance of comparing results by sex. Girls participated more than boys. Boys engage in more problem behaviors of all three types. The greatest surprise was that 11-year-old boys who bully and fight the most also engage in the most frequent civic participation. Group comparisons revealed that the hypothesized buffering effect of adolescent civic participation on the relationship between parent/family detachment and problem behaviors was found for girls but not boys. Especially for 15-year-olds detached from their parents and family, girls who participated more than 4 days per week engaged in less problem behavior whereas boys who participated at that level engaged in the most problem behavior, followed by boys who participated less than once per week. Boys who participated between 1 and 4 days per week engaged in the fewest problem behaviors, and thus suggesting a U-shaped relationship, again especially for 15-year-olds detached from family and parents.

The participation-by-family-detachment interaction indicates that this may be one of many mechanisms that connect civic participation to adolescent behavioral outcomes. Examination of the U-shaped relationship found for boys suggests high-levels of civic participation may have iatrogenic effects. One might be tempted to infer that this relationship between frequent participation and problem behaviors is spuriousdue to high detachment from family causing both behavioral problems and greater civic participation (to escape the home). The only problem with that interpretation is that detachment and participation are uncorrelated. An alternative explanation is that these results reflect a selection bias in which those youth engaging in the highest levels of participation may have been required to participate due to past behavioral problems (e.g., mandated community service). Alternatively, as with sports activity (Eitle et al., 2003), frequent civic participation may insert boys into a peer group, including more worldly youths, who may be more likely to use drugs and alcohol. Whatever the explanation, the results suggest that mandatory participation may have limited effectiveness as an intervention for adolescent males with severe behavior problems.

The trend toward a significant interaction and the curvilinear relationships suggest that the extent of involvement in civic engagement is important particularly as adolescents get older. The results suggest that the magnitude of the interaction increases with older adolescents. It may be that younger adolescents who participate have little choice or do so under parental influence, whereas participation may be more voluntary for most 15-year-olds (except for cases of mandatory service). It suggests that additional tests of this hypothesis with older adolescents and young adults are needed.

We must acknowledge that each of the problem behaviors we have examined (bullying, fighting, and alcohol and tobacco use) are different and may relate differently to civic participation. Past research on bullying, for example, suggests that the power differential found between the bully and victim may make the dynamics of this 
behavior different from that found in children who are experimenting with alcohol or tobacco or are fighting peers of equal power (Olweus, 1993). Also, in contrast to the other behavior problems, the subtle nature of bullying allows it to occur even in structured situations. In fact, some studies have found that the most frequent location of bullying was in the classroom (e.g., Wolke, Woods, Stanford, \& Schulz, 2001). Structured civic participation may not have the desired effect on bullying without instilling in youth a deeper, more intrinsic motivation for civic engagement. This highlights the need for additional research on the various meanings of civic engagement to adolescent boys and girls at different stages of social and moral development.

\section{LIMITATIONS AND STRENGTHS OF THE STUDY}

The present data have several notable strengths and limitations. The principal limitation is the small amount of information available on the exact nature of students' participation in civic activities. We do know that most of the respondents who reported some civic engagement participated in faith-based organizations; but, it should be noted that in Italy (unlike in the United States) the local church is one of the few institutional options for civic engagement and it operates a variety of service programs (Marta et al., 1999). Future research is needed with more detailed information regarding levels of civic participation, kinds of activities, and how those activities provide structure and positive ideological frameworks for youth. Second, the present analyses only focus on frequency of involvement and not on the nature or quality of participation in activities or the support from the activity leader or parents to get involved. Third, in a cross-sectional study, it is not possible to determine the stability and the direction of the effects between civic participation and adolescent problematic behaviour over time. Longitudinal studies of civic participation are needed to substantiate the cross-sectional findings of this study. Future research should also use different informants, such as parents, teachers, and activity leaders to compare with adolescents' self reports. Finally, space limitations prevented an examination of competence outcomes, but they should also be considered.

The strengths of the study include a large and representative sample, three different age groups, a measure of the frequency of participation (as opposed to a dichotomous measure), and the fact that it permits cross-cultural comparisons with results from other countries. International research is underrepresented in the U.S. community psychology literature. This study provides insights into the effects of youth civic engagement in a larger social context, which may be more common than that of the U.S.: Italy has an extensive state-run human service system and community service opportunities dominated by a single religious institution.

\section{CONGLUSIONS}

Our results suggest that civic engagement may play a useful role in a comprehensive approach to health promotion among adolescents. This is consistent with the research on service learning, which has indicated that adolescents engaged in community service often benefit as much or more than the recipients of the service (O'Donnell et al., 1999). Our results also show, however, that health and civic-oriented youth development programs must pay closer attention to sex as well as age differences in participation and its effects and to the frequency of participation. For boys, a caution in these data are that daily participation may have unexpected negative consequences 
for their health and social behavior. But the encouraging conclusion is that for girls and in moderation for boys, civic engagement is linked to fewer problem behaviors.

\section{REFERENCES}

Aarø, L.E., Wold, B., Kannas, L., \& Rimpelä, M. (1986). Health behaviour in schoolchildren. A WHO cross-national survey. Health Promotion, 1, 17-33.

Allen, J.P., Philliber, S., Herrling, S., \& Kuperminc, G.P. (1997). Preventing teen pregnancy and academic failure: Experimental evaluation of a developmentally based approach. Child Development, 68, 729-742.

Barber, B.L., Eccles, J.S., \& Stone, M.R. (2001). Whatever happened to the jock, the brain, and the princess? Young adult pathways linked to adolescent activity involvement and social identity. Journal of Adolescent Research, 16, 429-455.

Barnes, G.M., Reifman, A.S., Farrell, M.P., \& Dintcheff, B.A. (2000). The effects of parenting on the development of adolescent alcohol misuse: A six-wave latent growth model. Journal of Marriage and the Family, 62, 175-186.

Bartko, W.T., \& Eccles, J.S. (2003). Adolescent participation in structured and unstructured activities: A person-oriented analysis. Journal of Youth and Adolescence, 32, 233-241.

Biederman, J., Faraone, S.V., \& Monuteaux, M.C. (2002). Differential effect of environmental adversity by gender: Rutter's index of adversity in a sample of boys and girls with and without ADHD. American Journal of Psychiatry, 159, 1556-1562.

Brener, N.D., Collins, J.L., Kann, L., Warren, C.W., \& Williams, B.I. (1995). Reliability of the youth risk behavior survey questionnaire. American Journal of Epidemiology, 141, 575-580.

Bronfenbrenner, U. (1979). The ecology of human development. Cambridge, MA: Harvard University Press.

Brown, T.N., Schulenberg, J., Bachman, J.G., O’Malley, P.M., \& Johnston, L.D. (2001). Are risk and protective factors for substance use consistent across historical time?: National data from the high school classes of 1976 through 1997. Prevention Science, 2, 29-43.

Chassin, L., Curran, P.J., Husson, A.M., \& Colder, C.R. (1996). The Relation of parent alcoholism to adolescent substance use: A longitudinal follow-up study. Journal of Abnormal Psychology, 105, 70-80.

Cowen, E.L. (1994). The enhancement of psychological wellness: Challenges and opportunities. American Journal of Community Psychology, 22, 149-179.

Curtner-Smith, M.E. (2000). Mechanisms by which family processes contribute to school-age boy's bullying. Child Study Journal, 30, 169-186.

Dishion, T.J., \& Bullock, B.M. (2002). Parenting and adolescent problem behavior: An ecological analysis of the nurturance hypothesis. In J.G. Borkowski (Ed.), Parenting and your child's world (pp. 231-250). Hillsdale, NJ: Erlbaum.

Dodge, K.A. (2001). The science of youth violence prevention. Progressing from developmental epidemiology to efficacy to effectiveness to public policy. American Journal of Preventative Medicine, 20, 63-70.

Eccles, J.S., \& Barber, B.L. (1999). Student council, volunteering, basketball, or marching band: What kind of extracurricular involvement matters? Journal of Adolescent Research, 14, $10-43$.

Eitle, D., Turner, R.J., \& Eitle, T.M. (2003). The deterrence hypothesis reexamined: Sports participation and substance use among young adults. Journal of Drug Issues, 33, 193-222.

Espelage, D., Bosworth, K., \& Simon, T.R. (2000). Examining the social context of bullying behaviors in early adolescence. Journal of Counseling and Development, 78, 326-333. 
Farrington, D.P., Loeber, R., Yin, Y., \& Anderson, S.J. (2002). Are within-individual causes of delinquency the same as between-individual causes? Criminal Behaviour and Mental Health, $12,53-68$.

Fletcher, A.C., Elder, G.H., Jr., \& Mekos, D. (2000). Parental influences on adolescent involvement in community activities. Journal of Research on Adolescence, 10, 29-48.

Flouri, E., \& Buchanan, A. (2003). The role of mother involvement and father involvement in adolescent bullying behavior. Journal of Interpersonal Violence, 18, 634-644.

Formoso, D., Gonzales, N.A., \& Aiken, L. (2000). Family conflict and children's internalizing and externalizing: Protective factors. American Journal of Community Psychology, 28, 175199.

Garnier, H.E., \& Stein, J.A. (2002). An 18-year model of family and peer effects on adolescent drug use and delinquency. Journal of Youth and Adolescence, 31, 45-56.

Gilman, R. (2001). The relationship between life satisfaction, social interest, and frequency of extracurricular activities among adolescent students. Journal of Youth and Adolescence, 30, $749-767$.

Gorman-Smith, D., Tolan, P.H., Zelli, A., \& Huesmann, L.R. (1996). The relation of family functioning to violence among inner-city minority youths. Journal of Family Psychology, 10, $115-129$.

Henry, D.B., Tolan, P.H., \& Gorman-Smith, D. (2001). Longitudinal family and peer group effects on violence and nonviolent delinquency. Journal of Community Psychology, 30, $172-186$.

Johnson, V., \& Pandina, R.J. (1991). Effects of the family environment on adolescent substance use, delinquency, and coping styles. American Journal of Drug and Alcohol Abuse, 17, $71-88$.

Kinney, D.A. (1993). From nerds to normals: The recovery of identity among adolescents from middle school to high school. Sociology of Education, 66, 21-40.

Labouvie, E.W., Pandina, R.J., \& Johnson, V. (1991). Developmental trajectories of substance use in adolescence: Differences and predictors. International Journal of Behavioral Development, 14, 305-328.

Larson, R.W. (2001). How U.S. Children and adolescents spend time: What it does (and doesn't) tell us about their development. Current Directions in Psychological Science, 10, $160-164$.

Larson, R.W., \& Kleiber, D. (1993). Free time activities as factors in adolescents adjustment. In P. Tollan \& P. Cohler (Eds.), Handbook of clinical research and practice with adolescents (pp. 125-145). New York: Wiley.

Larson, R.W., \& Verma, S. (1999). How children and adolescents spend time across the world: Work, play, and developmental opportunities. Psychological Bulletin, 125, 701-736.

Lintonen, T., Rimpelae, M., Vikat, A., \& Rimpelae, A. (2000). The effect of societal changes on drunkenness trends in early adolescence. Health Education Research, 15, 261-269.

Mahoney, J.L. (2000). School extracurricular activity participation as a moderator in the development of antisocial patterns. Child Development, 71, 502-516.

Mahoney, J.L., Cairns, B.D., \& Farmer, T.W. (2003). Promoting interpersonal competence and educational success through extracurricular activity participation. Journal of Educational Psychology, 95, 409-418.

Mahoney, J.L., Schweder, A.E., \& Stattin, H. (2002). Structured after-school activities as a moderator of depressed mood for adolescents with detached relations to their parents. Journal of Community Psychology, 30, 69-86.

Mahoney, J.L., \& Stattin, H. (2000). Leisure activities and adolescent antisocial behavior: The role of structure and social context. Journal of Adolescence, 23, 113-127. 
Marsh, H.W., \& Kleitman, S. (2003). School athletic participation: Mostly gain with little pain. Journal of Sport and Exercise Psychology, 25, 205-228.

Marta, E., Rossi, G., \& Boccacin, L. (1999). Youth, solidarity, and civic commitment in Italy: An analysis of the personal and social characteristics of volunteers and their organizations. In M. Yates \& J. Youniss (Eds.), Roots of civic identity: International perspectives on community service and activism in youth (pp. 73-96). New York: Cambridge University Press.

McHale, S.M., Crouter, A.C., \& Tucker, C.J. (2001). Free-time activities in middle childhood: Links with adjustment in early adolescence. Child Development, 72, 1764-1778.

McNeal, R.B. (1995). Extracurricular activities and high school dropouts. Sociology of Education, $68,62-80$.

Mrazek, P.J., \& Haggerty, R.J. (1994). Reducing risks for mental disorders: Frontiers for preventive intervention research. Washington, DC: National Academy Press.

Nation, M., Crusto, C., Wandersman, A., Kumpfer, K.L., Seybolt, D., Morrissey-Kane, E., et al. (2003). What works in prevention: Principles of effective prevention programs. American Psychologist, 58, 449-456.

Nation, M., Wandersman, A., \& Perkins, D.D. (2002). Promoting healthy communities through community development. In L. Jason \& D. Glenwick (Eds.), Innovative strategies for promoting health and mental health across the life span (pp. 324-344). New York: Springer.

O’Donnell, L., Stueve, A., Doval, A.S., Duran, R., Atnafou, R., Haber, D., et al. (1999). Violent prevention and young adolescents' participation in community youth service. Journal of Adolescent Health, 24, 28-37.

Olweus, D. (1993). Bullying at school: What we know and what we can do. Cambridge, MA: Blackwell.

Olweus, D. (1996). The revised Olweus bully/victim questionnaire. Bergen, Norway: HEMIL, University of Bergen.

Parker, G., Tupling, H., \& Brown, L. (1979). A parental bonding instrument. British Journal of Medical Psychology, 52, 1-10.

Perkins, D.D., Crim, B., Silberman, P., \& Brown, B.B. (2003). Community development as a response to community-level adversity: Ecological theory and research and strengths-based policy. In K. Maton, C.J. Schellenbach, B.J. Leadbeater, \& A.L. Solarz (Eds.), Strengthsbuilding research and policy: Investing in children, youth, families, and communities (pp. 321340). Washington, DC: APA.

Pretty, G.M.H. (2002). Young people's development of the community-minded self: Considering community identity, community attachment and sense of community. In A.T. Fisher, C. Sonn, \& B. Bishop (Eds.), Psychological sense of community: Research, applications, and implications (pp. 183-203). New York: Kluwer Academic/Plenum.

Putnam, R.D. (2000). Bowling alone: the collapse and revival of American community. New York: Simon \& Schuster.

Rispens, J., Hermanns, J.M.A., \& Meeus, W.H.J. (1997). Opvoeden in Nederland (Parenting in the Netherlands). Assen, Netherlands: van Gorcum.

Sale, E., Sambrano, S., Springer, J.F., \& Turner, C.W. (2003). Risk, protection, and substance use in adolescents: A multi-site model. Journal of Drug Education, 33, 91-105.

Sandstrom, M., \& Coie, J.D. (1999). A developmental perspective on peer rejection: Mechanisms of stability and change. Child Development, 70, 955-966.

Sweeting, H., West, P., \& Richards, M. (1998). Teenage family life, lifestyles and life chances: Associations with the family structure, conflict with parents and joint family activity. International Journal of Law, Policy and the Family, 12, 15-46.

Thomas, G., Farrell, M.P., \& Barnes, G.M. (1996). The effects of single-mother families and nonresident fathers on delinquency and substance abuse in Black and White adolescents. Journal of Marriage and the Family, 58, 889-894.

Thompson, S.K. (1999). Sampling. New York: Wiley. 
Trembley, R.E., \& Craig, W.M. (1995). Developmental crime prevention. In M. Tonry \& D.P. Farrington (Eds.), Building a safer society: Strategic approaches to crime prevention (pp. 151236). Chicago: University of Chicago Press.

Werner, E.E. (1993). Risk, resilience, and recovery: Perspectives from the Kauai longitudinal study. Development and Psychopathology, 5, 503-515.

Wolke, D., Woods, S., Stanford, K., \& Schulz, H. (2001). Bullying and victimization of primary school children in England and Germany: Prevalence and school factors. British Journal of Psychology, 92, 673-696.

Yin, Z., Katims, D.S., \& Zapata, J.T. (1999). Participation in leisure activities and involvement in delinquency by Mexican American adolescents. Hispanic Journal of Behavioral Sciences, $21,170-185$.

Youniss, J., Bales, S., Christmas, B.V., Diversi, M., McLaughlin, M., \& Silbereisen, R. (2002). Youth civic engagement in the twenty-first century. Journal of Research on Adolescence, $12,121-148$.

Youniss, J., \& Yates, M. (1997). Community service and social responsibility in youth. Chicago: University of Chicago Press.

Youniss, J., Yates, M., \& Su, Y. (1997). Social integration: Community service and marijuana use in high school seniors. Journal of Adolescent Research, 12, 245-262. 